\title{
MEASUREMENT APPROACH OF MEAN HEAT TRANSFER COEFFICIENT FOR PACKED BED OF VEGETABLES
}

\author{
Adam ŁAPIŃSKI*, Dariusz BUTRYMOWICZ**, Mirosława KOŁODZIEJCZYK"*t* \\ *Department of Thermal Engineering and Refrigeration, Faculty of Mechanical Engineering, Bialystok University of Technology, \\ ul. Wiejska 45c, 15-351 Białystok, Poland
}

a.lapinski@doktoranci.pb.edu.pl, d.butrymowicz@pb.edu.pl, m.kolodziejczyk@pb.edu.pl

received 26 October 2016, revised 13 March 2017, accepted 15 March 2017

\begin{abstract}
The non-invasive measurement approach of the mean heat transfer coefficient for the packed bed of vegetables may be thought as still open issue. There is a clear need for the assessment of heat transfer conditions for various types of fruits and vegetables in order to accurately predict the thermal load that is necessary to select refrigeration equipment for cold storage chamber. Additionally, there is significant development in numerical modelling of heat and mass transfer processes in cold storage chambers for fruits and vegetables which requires precise heat transfer prediction. The theoretical basis for the indirect measurement approach of mean heat transfer coefficient for the packed bed of vegetables that is based on single blow technique is presented and discussed in the paper. The approach based on the modified model of Liang and Yang was presented and discussed. The testing stand consisted of a dedicated experimental tunnel along with auxiliary equipment and measurement system are presented. The geometry of the tested vegetables bed were presented. Selected experimental results of heat transfer are presented and discussed for the packed bed of carrots. These results were presented as dimensionless relationship. The obtained results were compared with the existing dimensionless relationships developed for the packed bed consisting of elements of various regular shapes.
\end{abstract}

Key words: Heat Transfer Coefficient, Packed Bed, Carrot, Single Blow Technique

\section{INTRODUCTION}

The paper deals with approach of the measurement of heat transfer and flow resistance in packed bed of vegetables. The knowledge of heat transfer conditions during cooling of vegetables is necessary for the reliable design of the cold storage chamber.

Usually measurement of the flow resistance in packed bed of vegetables or fruits is not very difficult. However, the measurement of the heat transfer coefficient may be thought as a challenge in most cases due to very complicated geometry of the packed bed elements. This is the reason why it is impossible to apply the simplest direct methods of the measurement of the heat transfer coefficient that are based on the direct measurement of the mean temperature of the vegetables surfaces, gas temperature distribution as well as heat flux density. This means that in this case an indirect method must be applied. The methodology of such measurement is proposed in this paper.

\section{INDIRECT MEASUREMENT METHODS}

The methods or techniques that can be applied to measure of the mean heat transfer coefficient in the packed bed can be classified in many ways. One of the possible classification approach that can be found in the literature is the classification proposed by Achenbach (2006) that is as follows:

- heat transfer measurement for a single spherical element located in the tested packed through which blows electrically heated air;

- techniques using the measurements of the mass transfer and the analogy between heat and mass transfer is applied;

- simultaneous exchange of heat and mass transfer approach;

- measurements involving the regenerative heating;

- semi-empirical method.

According to Achenbach (1995) a method using a blast of hot air flow involves determining temperature difference between the wall of the probe and its environment. Probe used in this method should be made in the form of a copper or brass sphere. Filling ambient probe should be characterized by a very low thermal conductivity. To eliminate the measurement error associated with the radiation of the probe surface is done by means of polishing of the sphere surface.

The technique of using of heat and mass transfer analogy is based on the measurement of weight loss with beads of naphthalene which sublimate during air flow in a specific period of time $\Delta t$. According to Achenbach (1995) the boundary condition in this technique is the substance concentration on the walls surface of the tested spheres.

Measurements using a simultaneous heat and mass transfer consists of placing the porous balls soaked with a liquid in air stream. In this method mass transfer is measured by loss in mass of the balls and the balls surface temperature which strongly depends on the process of evaporation. However, determination of the balls surface temperature causes considerable problems with application of this approach, Achenbach (1995).

Another method described by Achenbach (1995) is a regenerative heat technique. This technique involves simultaneous heat- 
ing and cooling of the tested packed bed. Temperature distribution is measured in this method which provides indirect information about heat transfer coefficient. The disadvantage of this technique is considerable technical and calculation efforts which strongly reduces the efficiency and accuracy of the measurement.

The last discussed method is a semi-empirical approach. It consists in determination of mean heat transfer on a single element of the regular shape for which the experimental correlations were obtained are transferred to the entire packed bed. Gnielinski (1978) successfully applied and described semiempirical method for the first time. He used the asymptotic solutions with laminar flow around a flat plate:

$N u_{l}=0,664 \operatorname{Pr}^{1 / 3}\left(\frac{R e}{\epsilon}\right)^{1 / 2}$

while for turbulent flow:

$N u_{t}=\frac{0,037 \operatorname{Pr}^{1 / 3}\left(\frac{R e}{\varepsilon}\right)^{0,8} \operatorname{Pr}}{1-2,443\left(\frac{R e}{\varepsilon}\right)^{-0,1}\left(\operatorname{Pr}^{2 / 3}-1\right)}$

where: $N u_{l}, N u_{t}$ is Nusselt number for laminar and turbulent flow, respectively; $P r$ is Prandtl number; $R e$ is Reynolds number; $\varepsilon$ is porosity of the packed bed.

Using eq. (1) and (2) are received the following correlation for Nusselt number $N u_{s p}$ for a single sphere:

$N u_{s p}=2+\left(N u_{l}^{2}+N u_{t}^{2}\right)^{1 / 2}$.

Another classification of the experimental methods of mean heat transfer in the packed bed was proposed by Fricke and Becker (2004). They classified methods as follows:

- the measurements at constant temperature;

- the measurement at a variable temperatures;

- heat flux measurements.

According to Becker and Fricke (2004) the most popular way to determine heat transfer coefficient is the measurement at variable temperatures. The measurement at variable temperatures consists on the determination of heat transfer coefficient during heating or cooling of the product. During the measurements two cases are possible: low Biot number $(B i \leq 0.1)$, and high Biot number $(B i>0.1)$.

The Biot number, $\mathrm{Bi}$, can be defined as the ratio of external heat transfer resistance to internal heat transfer resistance, and is defined as follows:

$B i=\frac{\alpha Z}{\lambda}$.

The first case, i.e. small Bi number means negligible internal thermal resistance, i.e. in all of the tested elements temperature is very uniform at a given point in time. For a case of high Biot Number the thermal resistance affects temperature distribution in the tested element, i.e. at the same time in the tested objects temperature gradient will appear. During cooling process by cold air flow the typical range of Biot number is $0.2<B i<20$. Therefore internal thermal resistance is important during cooling or freezing of foodstuff. A method involving the internal temperature gradient of food products is useful to determine heat transfer coefficient in the case of elements of a simple regular shape, e.g. flat plateshaped elements, cylinders or spheres (Becker and Fricke 2004).

A different approach for measurement of heat transfer coefficient was proposed by Alvarez et al. (1999a, b). They conducted the measurement of transfer coefficient using non-steady methods. They heated balls made of aluminium inside which were placed thermocouples. Such constructed spheres first were heated up to $60^{\circ} \mathrm{C}$ and then placed in the boxes, and finally are cooled in an air stream. The authors (Alvarez et al. 1999b), defined the heat transfer coefficient of the balance sheet:

$\alpha A\left(T-T_{0}\right)=\rho V c_{p} \frac{d T}{d t}$

where: $T$ - temperature of the ball; $T_{0}$ - air temperature; $\rho$ - density of the ball; $c_{p}$ - specific heat of the ball material; $t$ - time; $V$ - volume of the ball; $A$ - surface area of the ball; $\alpha$ - heat transfer coefficient.

For the case of bed consisted of balls, Alvarez et al. (1999a,b)proposed the following empirical correlation:

$N u=2+3,78 R e^{0,44} \mathrm{Tu}^{0,33} \operatorname{Pr}^{0,33}$

where: $T u$ is turbulence intensity.

Studies on the heat transfer in the bed are also carried out by Laguerre et al. $(2006,2008)$. In both cases, tests were performed with use of the spherical objects. The investigations of Laguerre et al. (2006) were performed to study of heat transfer between of the bed and the container wall. They used balls made of aluminium and steel in the measurements. Balls were additionally coated with chrome in order to eliminate the effect of radiation. Additionallythey put in the bed two balls: heating and the heated in order to determine of heat conduction in the bed. Laguerre et al. (2008) studied heat transfer for the case of natural convection in the bed of balls made of PVC filled with gel.

Detailed overview and summary of the heat transfer coefficients for food products, along with the existing correlations, helpful in determining the value of transfer coefficients includes ASHRAE Handbook - Refrigeration (2010).

All of the above approaches may be thought as unsuitable for measurement of mean heat transfer coefficient of the packed bed of vegetables since in most of these techniques the various shapes of the vegetables could not be taken into account as well as there is possible significant change of the vegetables thermokinetic properties during the measurement procedure. The above disadvantages may be omitted by means of application of the purely indirect method, i.e. single blow technique. To the knowledge of the authors this technique has never been applied for the measurement of the mean heat transfer coefficient of the packed bed of vegetables. Therefore the application of this technique as well as preparation of the appropriate methodology dedicated for the packed bed of vegetables is the motivation of the authors for present investigations reported in this paper.

\section{SINGLE BLOW METHOD}

The so-called single blow technique is thought to be an efficient method used to experimentally determine the average heat transfer coefficient $\alpha$ in the packed bed. This method was also effectively applied for investigations of heat transfer in compact heat exchangers: Shaji and Das (2010), Krishnakumar et al. (2011), Ranganayakulu et al. (2017). Heat transfer coefficient is based on the actual surface area of the bed elements and takes into account convective heat transfer between gas and the packed bed element surface. In the discussed method the average heat transfer coefficient a to be found is determined by means of the comparison of the actual temperature profile of gas (that is heated or cooled in the tested packed bed) measured at the outlet of the tested packed bed with the predicted one on the basis of the 
theoretical model, Butrymowicz et al. (2016). The agreement between the experimental temperature profiles and theoretical prediction depends on the heat transfer coefficient $\alpha$ that is applied in the theoretical model of heat transfer. Various theoretical approaches may be applied in order to predict temperature profile at the outlet for given inlet conditions and the vegetables geometry. Below short review of theoretical models which may be applied in the single blow method is presented.

The measurement in the single blow method is to record the time variability of gas temperature profile directly at the inlet and outlet of the tested packed bed which is caused by switching the heating section on or off is of key importance for the discussed method. The following conditions need to be met before the measurement:

- gas flow is steady state (constant velocity);

- the temperature in the measurement section is constant and equal in the axial and radial directions.

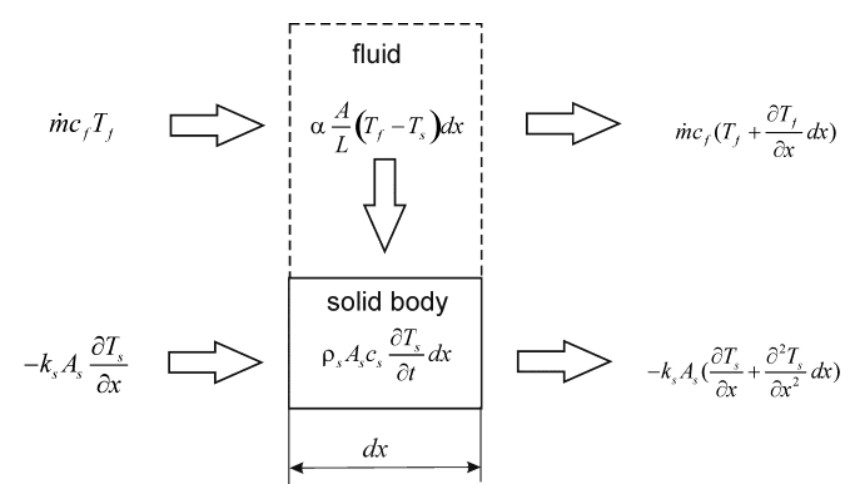

Fig. 1. Energy balance for fluid (f) and solid body (s) for the packed bed element

Temperature profiles should be measured for different velocities, involving the whole range of Reynolds numbers expected in the range of the operating conditions of the packed bed.

Temperature profiles recorded during the single blow technique measurements are used when solving equations modelling heat exchange in the tested packed bed. The measured temperature leap or profile at the inlet to the test section is the boundary condition for the model equations. The measured temperature profile at the outlet of the test section should be predicted on the basis of the model. However, the theoretical and the measured outlet temperature profiles may be compared in several ways that may be thought as equivalent.

The most basic one-dimensional model of transient heat transfer between a porous body and a fluid flowing through it is the model proposed by Anzelius (1926). This model became the basis for many further modifications and is still being developed by removing the numerous simplifications assumed by the author in order to obtain analytical solution of the model equations. Anzelius (1926) model is based on the energy balance for a solid body element (porous or perforated packing of the exchanger) in the situation presented in Fig. 1.

The following assumptions were made:

- the physical properties of fluid are independent of temperature;

- gas flow is steady state $(m=$ const);

- the solid has a homogeneous structure;

- the thermal conductivity perpendicular to the flow direction is infinite (both for the fluid and for the solid body);
- the thermal conductivity of the fluid in the flow direction equals to zero;

- the external casing of the packed bed is adiabatic;

- initially the temperature in the exchanger is uniform $\left(T_{s}=T_{f}=\right.$ $\left.T_{i}\right)$;

- initially the fluid temperature leaps from $T_{i}$ to $T_{f 1}$ and then it remains steady.

Balance equations of the element of fluid and solid body are as follows:

$\frac{\partial T_{f}}{\partial z}=T_{S}-T_{f}$,

$\frac{\partial T_{s}}{\partial \tau}=\lambda N T U \frac{\partial^{2} T_{S}}{\partial z^{2}}+\left(T_{f}-T_{s}\right)$

where: non-dimensional time is defined as follows:

$\tau=t \frac{\alpha A}{m_{s} c_{s}}$

and non-dimensional coordinate is defined as:

$z=N T U \frac{x}{L}$.

After the transformation of the above equations, two new coefficients appear in the energy balance for the solid body, namely the number of heat transfer units:

$N T U=\frac{\alpha A}{\dot{m} c_{f}}$

and a parameter connected with solid body thermal conductivity $\mathrm{k}_{\mathrm{s}}$ in the direction $\theta$ is parallel to the flow direction:

$\lambda=\frac{k_{S} A_{s}}{\dot{m} c_{f} L}$.

If the conductivity can be ignored, the above equations have analytical solutions developed by Schumann (1929) in the form:

$\theta_{z}=1-e^{-(z+\tau)} \sum_{n=0}^{\infty} z^{n} \frac{d^{n}}{d(z \tau)^{n}}\left(J_{0}(2 i \sqrt{z \tau})\right)$,

$\theta_{f}=1-e^{-(z+\tau)} \sum_{n=1}^{\infty} z^{n} \frac{d^{n}}{d(z \tau)^{n}}\left(J_{0}(2 i \sqrt{z \tau})\right)$

where: $\theta$ is non-dimensional temperature defined as follows

$\theta=\frac{T-T_{i}}{T_{f 1}-T_{i}}$.

The distributions of temperatures obtained from the above Schumann analytical solution can be used to determine the heat transfer coefficient $a$ if the experiment well agrees with the boundary and initial conditions assumed in the model. Then, comparing the measured temperature distribution $T_{f}(t)$ at the packed bed outlet with the theoretical temperature distribution the spot $z=N T U$, the best fit will be achieved if the value a specific for the tested exchanger is used (Furnas, 1932).

Instead of comparing the temperature profiles, their derivatives can be used, and in particular their maximum values. Locke (1950) differentiated the solution for the outlet temperature $T_{f 2}=T_{f}(\tau, z=N T U)$ at constant $N T U$ and obtained the relationship for the slope $S$ of the curve describing evolution of temperature $T_{f a}$ in dimensionless coordinates. This makes it possible to determine the derivative from the experimental profile of outlet temperature $T_{f 2}(t)$ and the experimental value $S_{\max }$. For that value it is possible to obtain the corresponding $N T U$ value, and then find the needed value of coefficient $\alpha$.

Solving the model equations taking into consideration heat 
conductivity along the solid body is only possible with numerical methods. The necessary calculations were done e.g. by Howard (1964), and his findings in the form of tables and graphs of function $N T U=f\left(S_{\max }\right)$ for selected values $\lambda$ within the range of $[0.005 \ldots 10, \infty]$ are also included in the paper presented by Pucci et al. (1967). The effect of the parameter $\lambda$ on the determination of $N T U$ is significant, especially when $N T U>10$. Due to the considerable slope of the curve $N T U=f\left(S_{\max }\right)$ this approach of determination of a with the use of maximum slope $S_{\max }$ involves considerable error for certain combinations of parameters $S_{\max }$ and $\lambda$.

The accuracy of determining of heat transfer coefficient using the single blow method can be improved by extending the Anzelius model, providing that:

- the leap of the inlet temperature of the fluid occurs not immediately;

- heat conductivity in the solid body occurs not only in the axial direction but also in the radial direction;

- the external wall of the packed bed (packed bed) is not adiabatic; consequently there is a radial temperature gradient in the packed bed;

- pressure drop of the fluid flowing through the packed bed (packed bed) causes change of its temperature due to JouleThomson effect;

- the distribution of fluid velocity in the axial direction is heterogeneous due to disturbances of gas flow occurring at the elements of the packed bed (packed bed).

The modification of the initial conditions of Schumann solution proposed by Liang and Yang (1975) minimizes the problems connected with experimental realization of the non-immediate temperature leap at the tested exchanger inlet. Liang and Yang model was further extended by Cai et al. (1984) by taking into consideration also the conductivity of the solid body in the axial direction. The solution of this model could be obtained by numerical procedure, however. In this case the temperature profile at the exchanger inlet can be any function of time. Chen and Chang (1996) added to the model an equation describing the heat transfer between fluid and the casing. They also took into account the Joule-Thomson effect (Chen and Chang, 1997), and finally also radial conductivity (Chang et al., 1999). Luo et al., 2001, highlighted the impact of disturbances of fluid flow caused by the elements of exchanger packing (so-called axial dispersion). Taking into consideration that the usually the measurements cover large number of test runs then the most useful will be the analytical solution of the temperature profile at the outlet of the tested packed bed, however.

One of the sources of inaccuracy of the heat transfer coefficient a determined by means of the single blow method is the difficulty of the realization of the immediate temperature leap at the exchanger inlet. Due to the thermal capacity of the heater any temperature changes always occur at a certain time span. Liang and Yang (1975) proposed the dimensionless inlet temperature profiles obtained in the discussed test method after switching the heater on or off as the exponential function:

$\theta_{f}(\tau, 0)=1-e^{-\tau / \tau^{*}}$

where: $\tau^{*}$ is an experimentally determined dimensionless constant.

The above temperature profile as the boundary condition for modified Anzelius model equations (Liang and Yang, 1975). In the equation for fluid energy balance its thermal capacity was taken into consideration so the equation for gas energy balance was obtained as follows:

$\frac{\partial \theta_{f}}{\partial \tau}+b_{1} \frac{\partial \theta_{f}}{\partial z}=b_{2}\left(\theta_{s}-\theta_{f}\right)$

The thermal conductivity in the solid body was ignored. In the dimensionless form energy balance equation for solid body can be presented as follows:

$\frac{\partial \theta_{s}}{\partial \tau}=\theta_{f}-\theta_{s}$.

The coefficients $b_{1}$ and $b_{2}$ in Eq. (17) are constant and defined as follows:

$b_{1}=b_{2} \frac{v_{f}}{A_{f, \min }}, \quad b_{2}=\frac{m_{s} m_{s}}{m_{f} m_{f}}$

where: $v_{f}$ is the volume of fluid inside the packed bed per length in the flow direction and $A_{f, \min }$ is the smallest cross-section surface area of the packed bed available for the flowing fluid. It must be remembered that temperature $T_{f 1}$, necessary to calculate $\theta$ should be the value settled at the inlet after a sufficiently long time after switching the heater on or off. Equations (17) and (18) with boundary condition Eq. (16) and the following initial conditions:

$\theta_{z}(0, z)=\theta_{f}(0, z)=0$

were solved (Liang and Yang, 1975) with the use of the Laplace transform which gave a set of equations:

$p \bar{\theta}_{f}+b_{1} \frac{d \bar{\theta}_{f}}{d z}=b_{2}\left(\bar{\theta}_{s}-\bar{\theta}_{f}\right)$,

$p \bar{\theta}_{s}=\bar{\theta}_{f}-\bar{\theta}_{s}$,

$\bar{\theta}_{f}(p, 0)=\frac{1}{\tau^{*} p\left(p+\frac{1}{\tau^{*}}\right)}$

where: $\bar{\theta}$ denotes the transform, and $p$ is its argument. The solution to the set of Eqs. (21)-(23) in relation to $\bar{\theta}_{f}$ is as follows (Liang and Yang, 1975):

$\bar{\theta}_{f}=\frac{\exp \left(-\frac{p}{b_{1}}\left(1+\frac{b_{2}}{1+p}\right) z\right)}{\tau^{*} p\left(p+\frac{1}{\tau^{*}}\right)}$.

Finding the inverse Laplace transform for Eq. (25) at $z=$ $N T U$, the following relationships describing the profile of dimensionless temperature at the packed bed outlet are obtained:

- if $\tau<t^{*}$ (i.e.: $t<L / w_{f}$ ):

$\theta_{f}(\tau, N T U)=0$,

- b) when $\tau \geq t^{*}$ (i.e. $t \geq L / w_{f}$ ):

$\theta_{\mathrm{f}}(\tau, \mathrm{NTU})=$

$\frac{1}{\tau^{*}} \int_{\tau^{*}}^{\tau} \mathrm{e}^{-(\tau-\eta) / \tau^{*}-b_{2} \tau^{*}}\left\{\mathrm{e}^{-\left(\eta-\tau^{*}\right)} \mathrm{I}_{0}\left(2 \sqrt{\mathrm{b}_{2} \mathrm{t}^{*}\left(\eta-\mathrm{t}^{*}\right)}\right)+\right.$

$\left.\int_{0}^{\eta-t^{*}} e^{-\xi} I_{0}\left(2 \sqrt{b_{2} t^{*} \xi}\right) d \xi\right\} d \eta$.

In the above relationships the symbol $t^{*}$ denotes dimensionless time defined as follows:

$t^{*}=\frac{N T U}{b_{1}}$

and $w_{f}$ is the mean velocity of fluid in the packed bed.

Provided the relatively high numerical cost connected with the application of more complex mathematical models of heat transfer 
in regenerators, the authors decided that the use the above modified Liang and Yang model (Liang and Yang, 1975). The key element in this model is the consideration of the exponential character of the inlet temperature profile which allows to avoid a considerable error resulting from the impossibility to execute an immediate leap of temperature at the inlet of the tested packed bed. It is recognized that the accuracy of this model should be satisfactory for indirect measurement of the heat transfer coefficient.

\section{TEST APPARATUS}

The experimental part of the single blow method is carried out in a wind tunnel. Temperature and pressure measurement points are placed at the inlet and outlet of the tested packed bed. Static pressure difference is measured in order to determine the frictional flow resistance. In addition, the velocity of gas flow through the packed bed should be also measured. It may be suggested that the temperature of gas flowing through the packed bed should be raised above the ambient temperature by approximately $5-10 \mathrm{~K}$. An electrical heating coil made of resistance wires may be applied for this purpose. Due to the required velocity homogeneity, the heating coil should disturb the flow as little as possible. The structure of the coil also affects the gas temperature profile obtained after switching it on or off which is important from the point of view of the theoretical model applied to draw up the results of the measurements. The simplest models offer the analytical solutions for which an immediate temperature leap at the measurement section inlet is assumed. Some of the theoretical models assume the inlet temperature profile that is described by an exponential function achieved in the experiment. In more complicated numerical models there is no limitation concerning the profile of inlet temperature so the restrictions concerning the heating section (mainly its length in the direction of gas flow) are less important. Due to the homogeneity of velocity profiles required in the case of the theoretical models, it is recommended to place a flow straightened (in the form of a honeycomb packed bed) before the test section. In order to eliminate the influence of disturbances generated at the tunnel outlet geometry, a similar flow straightened should be also placed at the outlet of the test section. Reduction of the channel hydraulic diameter between the tunnel inlet and the test section is required in order to reduce turbulence level in the flow.

The test tunnel consists of three sections as it is show in Fig. 2. Air flow rate in the tunnel was controlled by means of change of the centrifugal exhaust fan rotational speed. The electric heater capacity was adapted to current operating conditions in order to produce the required air temperature jump. The electric heater capacity was fixed during the test run. The test stand consists of three parts:

- the inlet section with an electrical heater;

- the measurement section with the tested packed bed of vegetables;

- an exhaust fan with a diffuser.

The schematic of the test section is show in Fig. 3. The temperature distribution at the inlet and outlet to the test section were measured by means of thermocouples nets. Based on these measurements the average temperature of air at the inlet and outlet were obtained under transient operating conditions.

The following basic parameters are measured on the test stand:
- air temperature at the tunnel inlet:

- air temperature at the tested bed inlet ;

- air temperature at the tested bed outlet;

- static pressure drop at the tested bed;

- dynamic pressure at the tunnel inlet;

- air humidity at the channel inlet and outlet;

- electric heater on/off signal.

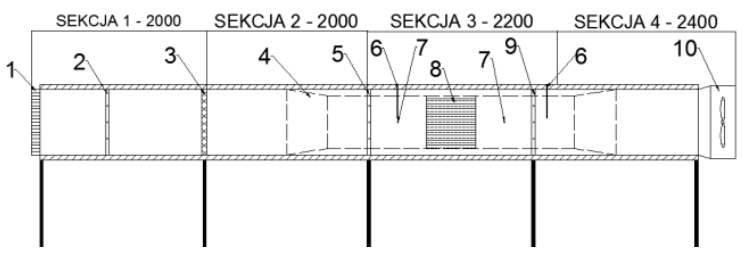

Fig. 2. Schematic diagram of the test tunnel: 1 - flow rectifier; 2 - air flow rate and temperature sensors; 3 - electric air heater; 4 - confusor/diffuser; 5 - thermocouples net at the tested bed inlet; 6 - moisture sensors; 7 - pressure gauges; 8 - tested packed bed of vegetables; 9 - thermocouples net at the tested bed outlet; 10 -exhaust fan

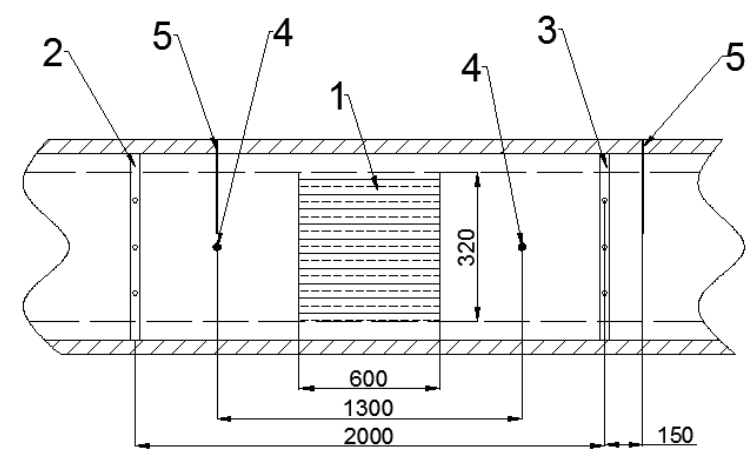

Fig. 3. Schematic of the test section: 1 - tested packed bed; 2 - thermocouples net at the bed inlet; 3 - thermocouples net at the bed outlet; 4 - pressure gauges; 5 - air moisture sensors

Thermocouples of the type of TP201 $\mathrm{J}$ of the diameter $0.5 \mathrm{~mm}$ were placed. The thermocouples of the open junction type were applied which enabled low thermal inertia. The thermocouples were calibrated for three temperature levels with use of the calibrated Pt100 sensor. The maximum difference between calibration sensor readings and thermocouples readings were not exceed $\pm 0.15 \mathrm{~K}$.

The reported measurements were carried out for the case of carrot. The prepared packed bed of carrot before insertion in the test tunnel were show in Fig. 4 and Fig. 5. The tested carrot was inserted in the gauze container.

The dimensions of the prepared packed bed were as follows: width $0.320 \mathrm{~m}$; height $0.320 \mathrm{~m}$; length $0.600 \mathrm{~m}$.

The parameters of tested carrots placed in the bed are reported in Tab. 1. Carrots in this table have been classified by weight every $5 \mathrm{~g}$.

Parameters of the tested bed of carrot:

- average mass: $m_{b}=32.27 \mathrm{~kg}$;

- average heat transfer surface area: $A_{p}=4.8 \mathrm{~m} 2$;

- average volume: $V=0.0363 \mathrm{~m} 3$;

- average density: $\rho=1.007 \mathrm{~kg} / \mathrm{dm} 3$. 


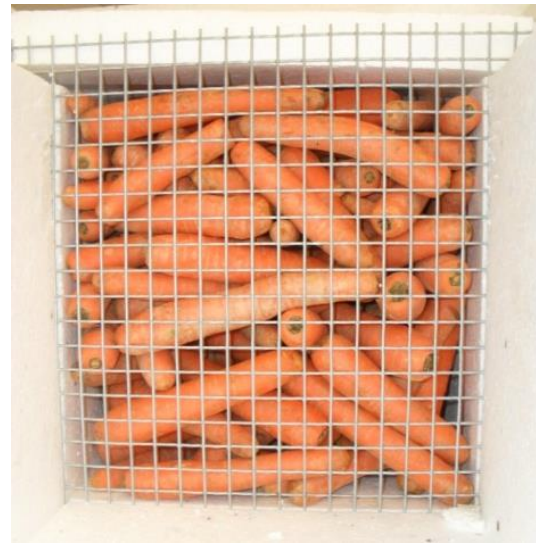

Fig. 4. The packed bed of carrot (inlet bed)

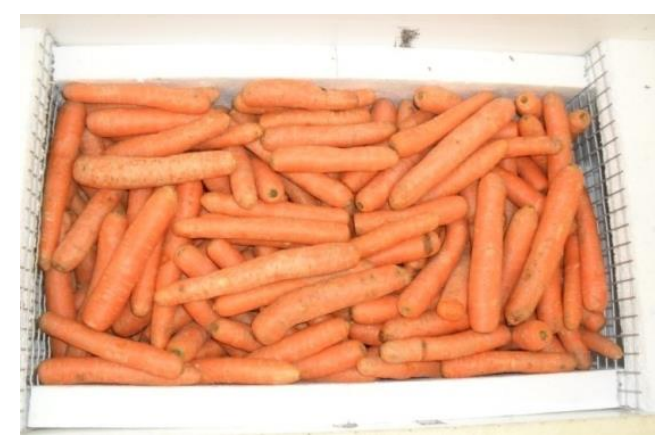

Fig. 5. The packed bed of carrot (view from above)

Tab. 1. Parameters carrots in bed

\begin{tabular}{|c|c|c|c|c|c|}
\hline $\begin{array}{c}\text { Range } \\
\text { weight } \\
\text { [g] }\end{array}$ & $\begin{array}{c}\text { Amo } \\
\text { unt }\end{array}$ & $\begin{array}{l}\text { Average } \\
\text { mass [g] }\end{array}$ & $\begin{array}{c}\text { Average } \\
\text { volume } \\
{\left[\mathrm{dm}^{3}\right]}\end{array}$ & $\begin{array}{c}\text { Average } \\
\text { surface } \\
\text { area }\left[\mathrm{dm}^{2}\right]\end{array}$ & $\begin{array}{c}\text { Average } \\
\text { density } \\
{\left[\mathrm{kg} / \mathrm{dm}^{3}\right]}\end{array}$ \\
\hline $55-60$ & 15 & 57 & 0.056 & 1.036 & 1.005 \\
\hline $60-65$ & 18 & 61 & 0.060 & 1.110 & 1.020 \\
\hline $65-70$ & 21 & 67 & 0.065 & 1.066 & 1.030 \\
\hline $70-75$ & 25 & 72 & 0.071 & 1.191 & 1.014 \\
\hline $75-80$ & 27 & 78 & 0.076 & 1.247 & 1.018 \\
\hline $80-85$ & 23 & 83 & 0.080 & 1.272 & 1.038 \\
\hline $85-90$ & 19 & 87 & 0.085 & 1.408 & 1.024 \\
\hline $90-95$ & 23 & 92 & 0.093 & 1.480 & 0.989 \\
\hline $95-100$ & 15 & 97 & 0.099 & 1.444 & 0.987 \\
\hline $100-105$ & 15 & 102 & 0.100 & 1.527 & 1.014 \\
\hline $105-110$ & 15 & 107 & 0.107 & 1.597 & 1.002 \\
\hline $110-115$ & 20 & 112 & 0.110 & 1.573 & 1.010 \\
\hline $115-120$ & 17 & 118 & 0.112 & 1.675 & 1.053 \\
\hline $120-125$ & 11 & 121 & 0.124 & 1.684 & 0.979 \\
\hline $125-130$ & 13 & 127 & 0.126 & 1.657 & 1.012 \\
\hline $130-135$ & 12 & 133 & 0.152 & 1.892 & 0.874 \\
\hline $135-140$ & 7 & 136 & 0.137 & 1.735 & 0.988 \\
\hline $140-145$ & 6 & 142 & 0.141 & 1.866 & 1.006 \\
\hline $145-150$ & 9 & 147 & 0.141 & 1.967 & 1.037 \\
\hline $150-155$ & 10 & 152 & 0.148 & 1.950 & 1.026 \\
\hline $155-160$ & 3 & 157 & 0.159 & 2.100 & 0.986 \\
\hline $160-165$ & 5 & 163 & 0.164 & 2.019 & 0.996 \\
\hline
\end{tabular}

The average hydraulic diameter of the packed bed $d_{h}$ may be assessed on the basic of porosity: $d_{h}=\frac{4 A_{p w l}}{U_{p}}=\frac{4 V_{p}}{A_{p}}$

where: $A_{p w l}$ - surface area of the free space inlet; $U_{p}$ - perimeter of the free space inlet; $V_{p}\left(A_{p w l} \cdot L\right)$ - volume of free space; $A_{p}\left(U_{p} \cdot L\right)$ - surface area of free space; $L$ - length of the bed.

Knowing that the porosity $(\varepsilon)$ and specific surface area $(a)$ the following relationship may be applied:

$\epsilon=\frac{V_{p}}{V} ; a=\frac{A_{p}}{V}$,

where: $V$ - total volume of the bed. Substituting equation (29) to (28) it may be obtained:

$d_{h}=4 \frac{\epsilon}{a}$.

\section{TEST RESULTS}

The obtained results based on the application of the described single blow technique for the packed bed of carrots were presented in Tab. 2. It should be noted that Reynolds number Re was based on flow parameters in the equivalent channel inside the packed bed and $w$ is velocity at the tested bed inlet. On the basis of the obtained experimental results the following correlation describing heat transfer in packed bed of carrots may be proposed:

$N u=0,308 \operatorname{Re}^{0,56} \operatorname{Pr}^{0,012}$

Tab. 2. Results of heat transfer measurements

\begin{tabular}{|c|c|c|c|c|c|c|c|}
\hline $\begin{array}{c}\mathbf{w} \\
{[\mathrm{m} / \mathbf{s}]}\end{array}$ & $\begin{array}{c}\Delta \mathbf{p} \\
{[\mathrm{Pa}]}\end{array}$ & $\mathbf{R e}$ & $\begin{array}{c}\mathbf{a} \\
{\left[\mathbf{W} / \mathbf{m}^{2} \mathbf{K}\right]}\end{array}$ & $\mathbf{N u}$ & $\mathbf{P r}$ & $\mathbf{j}$ & $\mathbf{f}_{\mathbf{D}}$ \\
\hline 0.096 & 0.545 & 268.304 & 11.2 & 6.55 & 0.524 & 0.03 & 0.9 \\
\hline 0.138 & 1.763 & 384.063 & 13.7 & 8.048 & 0.527 & 0.026 & 1.445 \\
\hline 0.19 & 2.083 & 531.895 & 18 & 10.673 & 0.532 & 0.025 & 0.874 \\
\hline 0.23 & 3.297 & 641.719 & 17.7 & 10.566 & 0.535 & 0.02 & 0.953 \\
\hline 0.283 & 4.302 & 791.88 & 20.6 & 12.206 & 0.531 & 0.019 & 0.812 \\
\hline 0.335 & 5.826 & 936.08 & 24 & 14.259 & 0.533 & 0.019 & 0.786 \\
\hline 0.397 & 7.407 & 1109 & 27.1 & 16.044 & 0.531 & 0.018 & 0.71 \\
\hline 0.437 & 9.065 & 1221 & 28.3 & 16.642 & 0.527 & 0.017 & 0.718 \\
\hline 0.49 & 10.866 & 1369 & 29.9 & 17.402 & 0.522 & 0.016 & 0.684 \\
\hline 0.556 & 12.862 & 1552 & 33 & 19.114 & 0.519 & 0.015 & 0.631 \\
\hline 0.599 & 14.982 & 1673 & 34.7 & 20.563 & 0.531 & 0.015 & 0.633 \\
\hline 0.638 & 17.319 & 1783 & 35 & 20.524 & 0.524 & 0.014 & 0.646 \\
\hline 0.684 & 19.492 & 1911 & 36 & 21.281 & 0.53 & 0.014 & 0.634 \\
\hline 0.74 & 21.949 & 2066 & 36.8 & 21.594 & 0.526 & 0.013 & 0.611 \\
\hline 0.798 & 24.621 & 2229 & 39.7 & 23.23 & 0.525 & 0.013 & 0.589 \\
\hline 0.838 & 27.277 & 2340 & 40.6 & 23.46 & 0.518 & 0.012 & 0.591 \\
\hline 0.892 & 30.209 & 2487 & 42 & 24.028 & 0.513 & 0.012 & 0.578 \\
\hline 0.938 & 33.328 & 2619 & 43 & 24.81 & 0.517 & 0.012 & 0.575 \\
\hline 0.992 & 36.775 & 2768 & 43.7 & 25.436 & 0.522 & 0.011 & 0.568 \\
\hline 1.029 & 40.341 & 2872 & 45.2 & 26.375 & 0.523 & 0.011 & 0.58 \\
\hline
\end{tabular}

The comparison of the measurement results with proposed dimensionless relationship eq. (31) is presented in Fig. 6.

Heat transfer coefficient $(\alpha)$ used in the measurement method, was presented as a heat transfer coefficient Colburn, which can be written as:

$j=\frac{N u}{\operatorname{RePr}^{1 / 3}}$, 


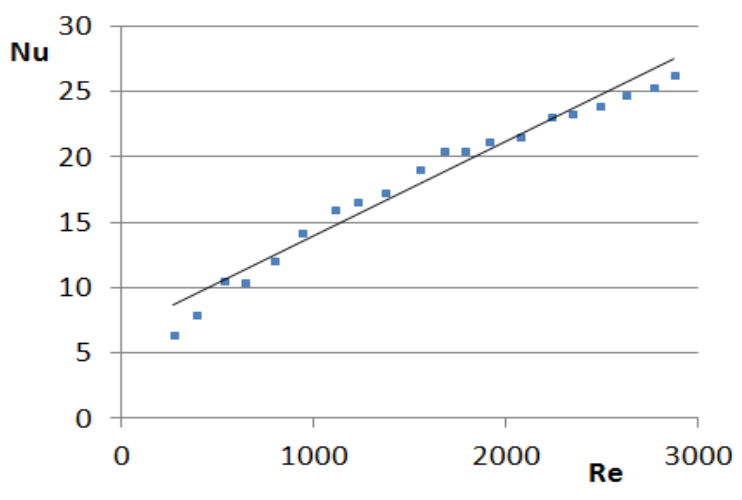

Fig. 6. Comparison of measured Nusselt number $\mathrm{Nu}$ with proposed correlation eq. (31)

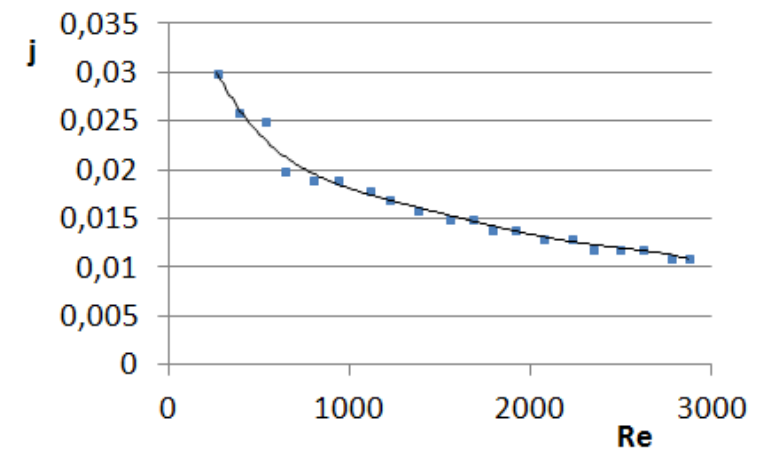

Fig. 7. Comparison of measured Colburn heat transfer factor $j$ with proposed correlation eq. (31) for the whole range of Reynolds number Re

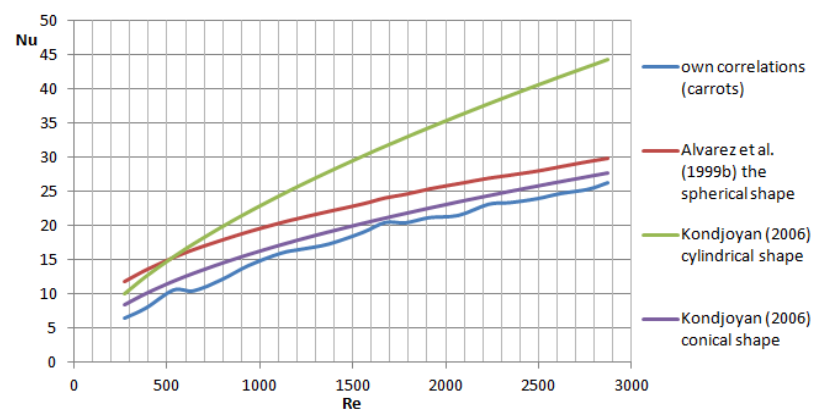

Fig. 8. Comparison of own correlation, eq. (31) for carrots with other correlations for regular shapes, eq. (33) $\div$ eq. (35)

Relationship between Colburn heat transfer factor versus Reynolds number is shown in Fig. 7.

The proposed own correlation may be compared with literature available correlations developed for the cases of the packed bed consisted of the elements of the regular shape:

- correlation proposed by Alvarez et al.(1999b) for the case of spherical shape:

$N u=2+3,78 R e^{0,44} \mathrm{Tu}^{0,33} \operatorname{Pr}^{0,33}$,

- correlation proposed by Kondjoyan (2006) for the case of the cylindrical shape:

$N u=0,31 R e^{0,62}\left(1+0,9 T u R e^{0,04}\right)$,

- correlation proposed by Kondjoyan (2006) for the case of the conical shape:
$N u=0,5 R e^{0,5}\left(1+0,87 T u R e^{0,09}\right)$.

The comparison between own correlation eq. (31) and other correlations developed for the packed bed consisted of the elements of the regular shape, eq. (33) $\div$ eq. (35) is presented in Fig. 8. It was assumed turbulence intensity $T u=0,02$ which corresponds to conditions of the test tunnel air flow. As it can be seen the analysed correlations eq. (33) $\div$ eq. (35) slightly over predicts own experimental correlation for Nusselt number for the whole range of Reynolds number except for the relationship eq. (34) developed for the cylindrical shape which strongly over predicts own results for higher Reynolds number range. However, it may be thought that the agreement between own correlation, eq. (31) and correlation developed for the conical shape, eq. (35) may be thought as reasonable good. Since the conical shape may be thought as the best geometry for the case of tested carrots the obtained results may be thought as the positive evaluation of the proposed measurement methodology of mean heat transfer coefficient for the packed bed of the vegetables.

\section{SUMMARY}

This paper presents the methodology of the measurement of heat transfer coefficients for packed bed composed of the vegetables. The reported measurements were carried out for the case of carrots. It is necessary to emphasize the necessity to develop an indirect method of measurement of the heat transfer coefficient by means of single blow technique. The current results involve the modification of this method proposed by Liang and Yang (Liang and Yang, 1975). The authors believe that the proposed methodology proved to be useful and produced reliable values of coefficients given by relationship eq. (30) for the tested packed bed of carrots. Further development of the proposed methodology may be proposed for the case of the other vegetables.

\section{REFERENCES}

1. Achenbach E. (1995), Heat and flow characteristics of packed beds, Experimental Thermal and Fluid Science, 10, 17-27.

2. Alvarez G., Bournet P.-E., Flick D. (2003). Two-dimensional simulation of turbulent flow and transfer through stacked spheres, International Journal of Heat and Mass Transfer, 46, 2459-2469.

3. Alvarez G., Flick D. (1999a), On heterogeneous cooling of agricultural products inside bins. Part I: aerodynamic study, Journal of Food Engineering, 39, 227-237

4. Alvarez G., Flick D. (1999b). On heterogeneous cooling of agricultural products inside bins. Part II: thermal study, Journal of Food Engineering, 39, 239-245,

5. ANSYS FLUENT 14.5 Theory Guide, 2012.

6. Anzelius A. (1926), On heating of bodies by flowing media, Zeitschrift für Angewandte Mathematik und Mechanik, 6(4), 291-294 (in German).

7. ASHRAE Handbook - Refrigeration (2010), chapter 19, page 19.119.31.

8. Becker B. R., Fricke B. A. (2004),Heat transfer coefficients for forced-air cooling and freezing of selected foods, International Journal of Refrigeration, 27, 540-551.

9. Ben Amara S., Laguerre O., Flick D. (2004). Experimental study of convective heat transfer during cooling with low air velocity in a stack of objects, International Journal of Thermal Science, 43, 1213-1221. 
10. Butrymowicz D., Karwacki J., Kwidziński R., Śmierciew K., Gagan J., Przybyliński T., Skiepko T., Łapin M., (2016), Methodology of heat transfer and flow resistance measurement for matrices of rotating regenerative heat exchangers, Chemical and Process Engineering, 37 (3), 341-358.

11. Cai Z.H., Li M.L., Wu Y.W., Ren H.S. (1984), A modified selected point matching technique for testing compact packed bed surfaces,International Journal of Heat and Mass Transfer, 27(7), 971-978.

12. Chang Z.-Ch., Hung M.-Sh., Ding P.-P., Chen P.-H. (1999), Experimental evaluation of thermal performance of Gifford-McMahon regenerator using an improved single-blow model with radial conduction, International Journal of Heat and Mass Transfer, 42, 405-413.

13. Chen P.-H., Chang Z.-Ch. (1996), An improved model for the singleblow measurement including the non-adiabatic side wall effect, International Communications in Heat and Mass Transfer, 23(1), 55-68.

14. Chen P.-H., Chang Z.-Ch. (1997), Measurements of thermal performance of cryocooler regenerators using an improved single-blow method, International Journal of Heat and Mass Transfer, 40(10), 2341-2349.

15. Defraeye T., Blocken B., Derome D., Nicolai B., Carmeliet J. (2012), Convective heat and mass transfer modelling at air-porous material interfaces: Overview of existing methods and relevance. Chemical Engineering Science, 74, 49-58.

16. Gnielinski E. (1978), Equations for calculation of heat and mass transfer in flow-through static ball beds with medium and large Peclet number, Verfahrenstechnik, 12(6), 63-366, (in German).

17. Howard C.P. (1964), The single blow problem including the effects of longitudinal conduction, ASME Paper No. 64-GTP-11, presented at Gas Turbine Conference and Product Show, Houston TX, USA.

18. Kays W.M., London A.L. (1997), Compact packed beds, McGrawHill.

19. Kondjoyan A. (2006), A review on surface heat and mass transfer coefficients during air chilling and storage of food products, International Journal of Refrigeration, 29, 863-875.

20. Krishnakumar K., John A.K., Venkatarathnam G. (2011), A review on transient test techniques for obtaining heat transfer design data of compact heat exchanger surfaces, Experimental Thermal and Fluid Science, 35, 738-743.
21. Laguerre O., Ben Amara S., Alvarez G., Flick D., (2008), Transient heat transfer by free convection in a packed bed of spheres: Comparison between two modelling approaches and experimental results, Applied Thermal Engineering, 28, 14-24

22. Laguerre O., Ben Amara S., Flick D., (2006), Heat transfer between wall and packed bed crossed by low velocity airflow, Applied Thermal Engineering, 26, 1951-1960

23. Liang C.Y., Yang. W.-J. (1975), Modified single-blow technique for performance evaluation on heat transfer surfaces, Transactions of the ASME Series C, Journal of Heat Transfer, 97, 16-21.

24. Locke G.L. (1950),Heat transfer and flow friction characteristics of porous solids, Technical Report No. 10, Department of Mechanical Engineering, Stanford University, Stanford CA, USA.

25. Luo X., Roetzel W., Lüdersen U. (2001), The single-blow transient testing technique considering longitudinal core conduction and fluid dispersion, International Journal of Heat and Mass Transfer, 44, 121129.

26. Pucci P.F., Howard C.P., Piersall C.H. Jr. (1967), The single-blow transient testing technique for compact packed bed surfaces, Trans. ASME,Journal of Engineering for Power, 89, 29-40.

27. Ranganayakulu C., Luo X., Kabelac S. (2017), The single-blow transient testing technique for offset and wavy fins of compact platefin heat exchangers, Applied Thermal Engineering, 111, 1588-1595.

28. Schumann T.E.W. (1929). Heat transfer: a liquid flowing through porous prism,J. Franklin Inst., 208(3), 405-416.

29. Shaji K., Das S.K. (2010),The effect of flow maldistribution on the evaluation of axial dispersion and thermal performance during the single-blow testing of plate heat exchangers, International Journal of Heat and Mass Transfer, 53, 1591-1602.

30. Verboven P., Datta A.K., Anh N.T., Scheerlinck N., Nikolai B.M. (2003), Computation of airflow effects on heat and mass transfer in a microwave oven, Journal of Food Engineering, 59, 181-190.

Acknowledgement: Research was performed as a part of projects MB/WM/9/2016and financed with use of funds for science of MNiSW. 